\title{
Chloroprocaine Hydrochloride
}

National Cancer Institute

\section{Source}

National Cancer Institute. Chloroprocaine Hydrochloride. NCI Thesaurus. Code C47444.

A synthetic, aminoester, local, anesthetic agent. At the injection site, chloroprocaine hydrochloride acts by inhibiting sodium influx through binding to specific membrane sodium ion channels in the neuronal cell membranes, restricting sodium permeability, and blocking nerve impulse conduction. This leads to a loss of sensation. Chloroprocaine hydrochloride is short-acting due to rapid hydrolysis by pseudocholinesterase into paraaminobenzoic acid in plasma. 